\title{
Interpreting the Estimates from the Full VECH Model with Asymmetry: The Case of US and Canadian Equity Prices
}

\author{
Chikashi Tsuji ${ }^{1}$ \\ ${ }^{1}$ Faculty of Economics, Chuo University, Tokyo, Japan \\ Correspondence: Chikashi Tsuji, Professor, Faculty of Economics, Chuo University, 742-1 Higashinakano, \\ Hachioji-shi, Tokyo 192-0393, Japan. E-mail: mail_sec_low@ minos.ocn.ne.jp
}

Received: September 22, 2017

Accepted: October 12, 2017

Online Published: October 17, 2017

doi:10.5430/afr.v6n4p236

URL: https://doi.org/10.5430/afr.v6n4p236

\begin{abstract}
This paper attempts to derive careful interpretation of the parameter estimates from one of the multivariate generalized autoregressive conditional heteroscedasticity (MGARCH) models, the full vector-half (VECH) model with asymmetric effects. We also consider and interpret the parameter estimates from a case study of US and Canadian equity index returns by applying this model. More specifically, we firstly inspect the model formula and derive general interpretation of the model parameters. We consider this is particularly useful for understanding not only the full VECH model structure but also similar MGARCH models. After the general considerations, we also interpret the case results that are derived from our application of the full VECH model to US and Canadian equity index returns. We consider that these concrete illustrations are also very helpful for future related research.
\end{abstract}

Keywords: Canadian stock market, VECH model, MGARCH model, US stock market

\section{Introduction}

In finance, the multivariate generalized autoregressive conditional heteroscedasticity (MGARCH) models are recently often used to time-series data (e.g., Sadorsky, 2012; Jayasinghe, Tsui, and Zhang, 2014; Guo, 2017). However, interpreting the results is not an easy task. This is because the structures of these models are rather complicated and understanding the model structures and parameter relations is not easy for applied or empirical researchers. Hence, it is highly important to consider how we can interpret the parameter estimates from these models to more clearly understand the results and estimates from these models.

Based on this motivation, this study attempts to derive general interpretation of the parameter estimates from one of the MGARCH models, the full vector-half (VECH) model with asymmetric effects. We also consider and interpret the parameter estimates from the case of US and Canadian equity index returns, where we apply this model. These two are the objectives of this study. More specifically, we firstly inspect the model formula and derive the general interpretation of the model parameters. We consider this is particularly useful for understanding not only the full VECH model structure but also similar other MGARCH models; and this is one of our contributions of this study. After the above general considerations, as we noted, we also interpret the case results that are derived from our application of the full VECH model to US and Canadian equity index returns. We consider that these concrete illustrations are also very helpful for future related research; and this is another contribution of this study.

After this introduction, Section 2 supplies a related research review; Section 3 explains our data and variables for our case study; and Section 4 describes the model. Section 5 presents the general interpretation of the model; Section 6 derives the interpretation of our case results; and in Section 7, we conclude the paper.

\section{Literature Review}

This section concisely reviews the preceding related studies, which used the VECH model. Estimations of large parameter sets in the VECH model are generally difficult; and thus, empirical studies in existing literature employing this VECH model are not many. Reviewing limited studies, first, Bollerslev, Engle, and Wooldridge (1988) applied a VECH model to the field of asset pricing. Using returns of bills, bonds, and stocks in the US, they showed a VECH model can be used to estimate the capital asset pricing model (CAPM), where the covariance of each return and market portfolio return was time-varying. They suggested that the conditional covariances largely varied over time, and they were important determinants of the time-varying risk premiums. Further, they also suggested that the betas derived from their model were also time-varying and forecastable. Baillie and Myers (1991) estimated the 
time-varying hedge ratios for commodity futures by applying a VECH model. They indicated that the assumption of a time-invariant optimal hedge ratio is inappropriate, and as an implication form their investigations, they also suggested that the estimated time-varying optimal hedge ratios were the non-stationary. Ferreira (2005) compared the time-varying covariance models using the data for the French and German interest rates of the pre-euro period. The empirical results from this study showed that, for their out-of-sample period, the variances and covariances forecasted by a VECH model were the best.

Füss, Mager, Wohlenberg, and Zhao (2011) examined the impact of German and US macroeconomic events on the implied volatility indices of Germany: VDAX, and that of US: VIX. They found that both volatility indices declined on announcement days, and the strongest reactions occurred during the financial crisis from 2008 to 2009. Degiannakis, Filis, and Floros (2013) investigated the time-varying correlations between oil and European industrial sector stocks. Using a VECH model and the stock return data from 10 European sectors, they found that the relationship between oil and sector stock returns in Europe changed over time and they were industry specific. As above, in existing studies, empirical applications using VECH models are limited.

\section{Data and Variables}

This section explains the data for our study. This study examines two daily international equity index returns. First is (1) the log percentage return of the S\&P 500 composite index in the US, which is denoted by LRSP; and second is (2) the log percentage return of the S\&P Toronto stock exchange composite index, which is denoted by LRTSX. Our analyzing sample period is from February 4, 1969 to January 31, 2017 and the return evolution is shown in Figure 1. From this figure, we understand that in general, the two return series show similar time-series evolution.

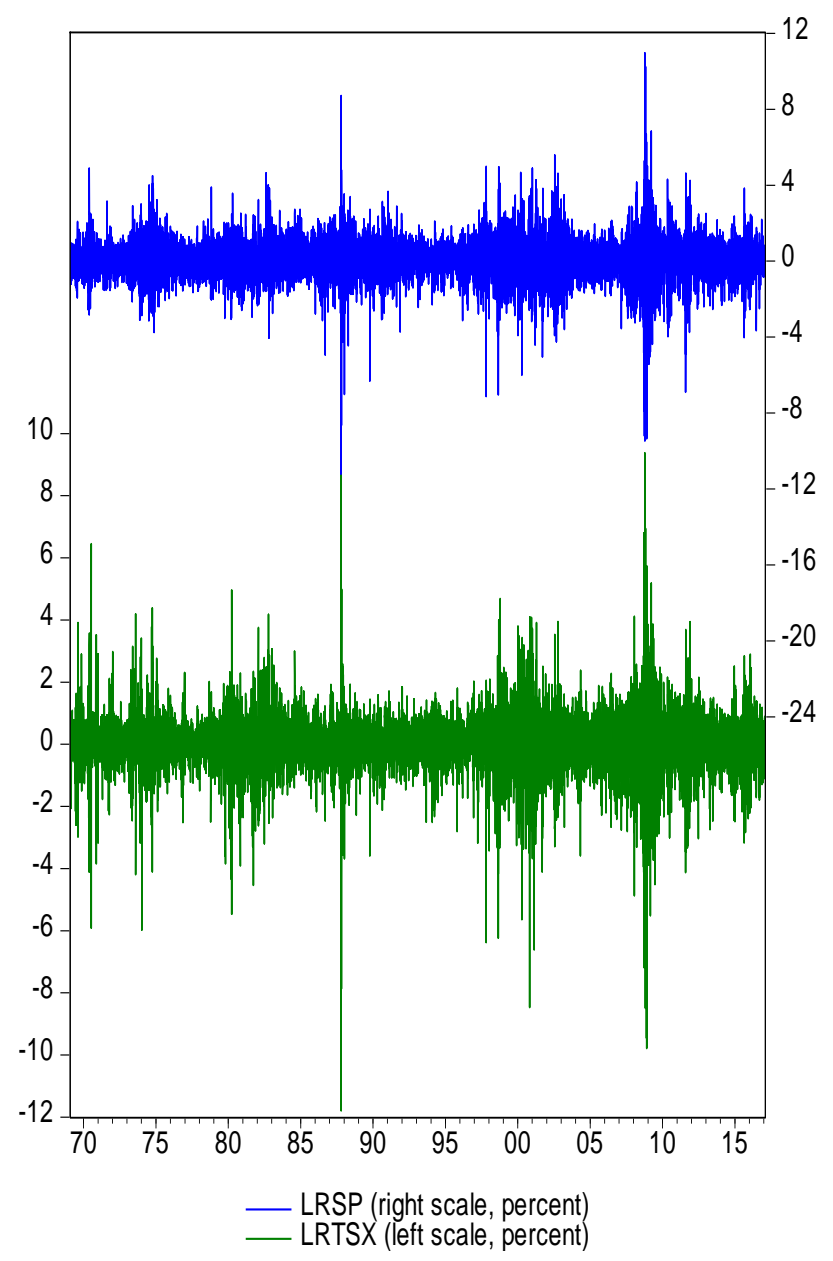

Figure 1. Dynamic evolution of the percentage log returns of US and Canadian equity indices: For the period from February 4, 1969 to January 31, 2017 
Table 1. Estimation results of the full VECH model with asymmetry for the US and Canadian equity index returns: For the period from February 4, 1969 to January 31, 2017

\begin{tabular}{|c|c|c|c|c|}
\hline \multicolumn{5}{|l|}{ Mean equations } \\
\hline Variables & Estimates & Standard error & $t$-statistic & $p$-value \\
\hline Constant of LRSP & $0.0244 * * *$ & 0.0065 & 3.7501 & 0.0002 \\
\hline Constant of LRTSX & $0.0333 * * *$ & 0.0054 & 6.1984 & 0.0000 \\
\hline \multicolumn{5}{|l|}{ VECH specifications } \\
\hline Variables & Estimates & Standard error & $t$-statistic & $p$-value \\
\hline $\mathrm{C}(1,1)$ & $0.0090 * * *$ & 0.0022 & 4.0563 & 0.0000 \\
\hline $\mathrm{C}(2,1)$ & -0.0008 & 0.0012 & -0.6810 & 0.4959 \\
\hline $\mathrm{C}(3,1)$ & $0.0588 * * *$ & 0.0090 & 6.5067 & 0.0000 \\
\hline $\mathrm{A}(1,1)$ & $0.0141 * *$ & 0.0060 & 2.3347 & 0.0196 \\
\hline $\mathrm{A}(1,2)$ & -0.0034 & 0.0119 & -0.2814 & 0.7784 \\
\hline $\mathrm{A}(1,3)$ & 0.0069 & 0.0069 & 0.9916 & 0.3214 \\
\hline $\mathrm{A}(2,1)$ & 0.0017 & 0.0037 & 0.4469 & 0.6550 \\
\hline $\mathrm{A}(2,2)$ & 0.0096 & 0.0085 & 1.1365 & 0.2558 \\
\hline $\mathrm{A}(2,3)$ & 0.0039 & 0.0055 & 0.7048 & 0.4809 \\
\hline $\mathrm{A}(3,1)$ & $0.0638 * * *$ & 0.0075 & 8.4919 & 0.0000 \\
\hline $\mathrm{A}(3,2)$ & $-0.1722 * * *$ & 0.0194 & -8.8796 & 0.0000 \\
\hline $\mathrm{A}(3,3)$ & $0.1509 * * *$ & 0.0152 & 9.9073 & 0.0000 \\
\hline $\mathrm{B}(1,1)$ & $0.9497 * * *$ & 0.0148 & 64.3683 & 0.0000 \\
\hline $\mathrm{B}(1,2)$ & $-0.0795 * *$ & 0.0362 & -2.1972 & 0.0280 \\
\hline $\mathrm{B}(1,3)$ & $0.0307 * *$ & 0.0152 & 2.0180 & 0.0436 \\
\hline $\mathrm{B}(2,1)$ & $0.0246 * * *$ & 0.0063 & 3.9321 & 0.0001 \\
\hline $\mathrm{B}(2,2)$ & $0.8396 * * *$ & 0.0146 & 57.4830 & 0.0000 \\
\hline $\mathrm{B}(2,3)$ & $0.0444 * * *$ & 0.0077 & 5.7521 & 0.0000 \\
\hline $\mathrm{B}(3,1)$ & $-0.4005 * * *$ & 0.0651 & -6.1530 & 0.0000 \\
\hline $\mathrm{B}(3,2)$ & $1.0524 * * *$ & 0.1841 & 5.7157 & 0.0000 \\
\hline $\mathrm{B}(3,3)$ & $0.5065^{* * *}$ & 0.0727 & 6.9677 & 0.0000 \\
\hline $\mathrm{D}(1,1)$ & $0.1037 * * *$ & 0.0116 & 8.9378 & 0.0000 \\
\hline $\mathrm{D}(1,2)$ & -0.0257 & 0.0218 & -1.1760 & 0.2396 \\
\hline $\mathrm{D}(1,3)$ & 0.0047 & 0.0103 & 0.4574 & 0.6474 \\
\hline $\mathrm{D}(2,1)$ & $0.0464 * * *$ & 0.0067 & 6.9695 & 0.0000 \\
\hline $\mathrm{D}(2,2)$ & -0.0135 & 0.0135 & -1.0053 & 0.3148 \\
\hline $\mathrm{D}(2,3)$ & $0.0146^{* *}$ & 0.0073 & 1.9856 & 0.0471 \\
\hline $\mathrm{D}(3,1)$ & $0.0466 * * *$ & 0.0098 & 4.7349 & 0.0000 \\
\hline $\mathrm{D}(3,2)$ & -0.0286 & 0.0240 & -1.1922 & 0.2332 \\
\hline $\mathrm{D}(3,3)$ & $0.0278 *$ & 0.0162 & 1.7199 & 0.0854 \\
\hline
\end{tabular}

Notes: This table presents the maximum likelihood estimation results of the full VECH models with asymmetric effects. The estimation is conducted for the period from February 4, 1969 to January 31, 2017. In this table, ***, $* *$, and * indicate the statistical significance of the model parameter estimates at the $1 \%, 5 \%$, and $10 \%$ levels, respectively. 


\section{The Model}

We next document the model. Namely, the full VECH model with asymmetric effects we analyze is as follows:

$$
\operatorname{vech}(\mathbf{H}(t))=\mathbf{C}+\mathbf{A} \operatorname{vech}\left(\mathbf{e}(t-1) \mathbf{e}(t-1)^{\prime}\right)+\mathbf{B} \operatorname{vech}(\mathbf{H}(t-1))+\mathbf{D} v e c h\left(\mathbf{v}(t-1) \mathbf{v}(t-1)^{\prime}\right) .
$$

In the application of model (1), this study uses only constant terms as the explanatory variables in the mean equations of LRSP and LRTSX. In model (1), $\mathbf{H}$ denotes the time-varying variance and covariance matrix and $\mathbf{e}$ means the matrix of the mean equation residuals. Further, $\mathbf{A}, \mathbf{B}, \mathbf{C}$, and $\mathbf{D}$ are coefficient matrices and $\mathbf{v}(t-1)=\mathbf{e}(t-1) \circ I_{e<0}(\mathbf{e}(t-1))$, where $\mathbf{e}(t-1)=\left[e_{1, t-1} e_{2, t-1}\right]^{\prime}, \quad \mathbf{v}(t-1)=\left[v_{1, t-1} v_{2, t-1}\right]^{\prime}$, and $\circ$ indicates the Hadamard product.

More concretely, we can write the variance equation of the first asset as follows:

$$
\begin{aligned}
\sigma_{1, t}^{2}= & C(1,1)+A(1,1) e_{1, t-1}^{2}+A(1,2) e_{1, t-1} e_{2, t-1}+A(1,3) e_{2, t-1}^{2} \\
& +B(1,1) \sigma_{1, t-1}^{2}+B(1,2) \sigma_{21, t-1}+B(1,3) \sigma_{2, t-1}^{2} \\
& +D(1,1) v_{1, t-1}^{2}+D(1,2) v_{1, t-1} v_{2, t-1}+D(1,3) v_{2, t-1}^{2} .
\end{aligned}
$$

Further, we can write the variance equation of the second asset as follows:

$$
\begin{aligned}
\sigma_{2, t}^{2}= & C(3,1)+A(3,1) e_{1, t-1}^{2}+A(3,2) e_{1, t-1} e_{2, t-1}+A(3,3) e_{2, t-1}^{2} \\
& +B(3,1) \sigma_{1, t-1}^{2}+B(3,2) \sigma_{21, t-1}+B(3,3) \sigma_{2, t-1}^{2} \\
& +D(3,1) v_{1, t-1}^{2}+D(3,2) v_{1, t-1} v_{2, t-1}+D(3,3) v_{2, t-1}^{2} .
\end{aligned}
$$

Moreover, the covariance of the first and second assets can be written as follows:

$$
\begin{aligned}
\sigma_{21, t}= & C(2,1)+A(2,1) e_{1, t-1}^{2}+A(2,2) e_{1, t-1} e_{2, t-1}+A(2,3) e_{2, t-1}^{2} \\
& +B(2,1) \sigma_{1, t-1}^{2}+B(2,2) \sigma_{21, t-1}+B(2,3) \sigma_{2, t-1}^{2} \\
& +D(2,1) v_{1, t-1}^{2}+D(2,2) v_{1, t-1} v_{2, t-1}+D(2,3) v_{2, t-1}^{2} .
\end{aligned}
$$

\section{General Interpretation of the Model Estimates}

First, we generally interpret the estimates for the variance of the first (second) asset. From equation (2) ((3)), regarding the effects of shocks in mean equations, a positive $A(1,1)(A(3,1))$ means a shock to the first asset affects the first (second) asset variance in the next period positively and a positive $A(1,3)(A(3,3))$ suggests a shock to the second asset affects the first (second) asset variance in the next period positively; while the coefficient $A(1,2)$ $(A(3,2))$ is difficult to interpret in general. As for the effects of variances and covariance, a positive $B(1,1)(B(3,1))$ indicates an increase of the first asset variance increases the first (second) asset variance in the next period and a positive $B(1,3)(B(3,3))$ means an increase of the second asset variance ups the first (second) asset variance in the next period. Assuming positive two asset covariances, a positive $B(1,2)(B(3,2))$ means an increase of the two asset covariance increases the first (second) asset variance in the next period. Further, as to the asymmetric effects, a positive $D(1,1)(D(3,1))$ means a negative shock to the first asset increases the first (second) asset variance in the next period and a positive $D(1,3)(D(3,3))$ means a negative shock to the second asset ups the first (second) asset variance in the next period. In addition, a positive $D(1,2)(D(3,2))$ suggests that when two assets have negative shocks simultaneously, these negative shocks increase the first (second) asset variance in the next period.

Next, we generally interpret the estimates for the covariance of the two assets. From equation (4), regarding the effects of shocks in mean equations, a positive $A(2,1)$ means a shock to the first asset affects the covariance in the next period positively and a positive $A(2,3)$ suggests a shock to the second asset affects the covariance in the next period positively; while the coefficient $A(2,2)$ is difficult to interpret in general. As to the effects of variances and covariance, a positive $B(2,1)$ indicates an increase of the first asset variance ups the covariance in the next period and a positive $B(2,3)$ means an increase of the second asset variance increases the covariance in the next period. Assuming positive two asset covariances, a positive $B(2,2)$ means an increase of the two asset covariance ups the covariance in the next period. Further, as for the asymmetric effects, a positive $D(2,1)$ means a negative shock to the first asset increases the covariance in the next period and a positive $D(2,3)$ means a negative shock to the second asset ups the covariance in the next period. In addition, a positive $D(2,2)$ suggests that when two assets have negative shocks simultaneously, these negative shocks increase the covariance in the next period. 
Panel A. Time-varying variances of US equity index returns

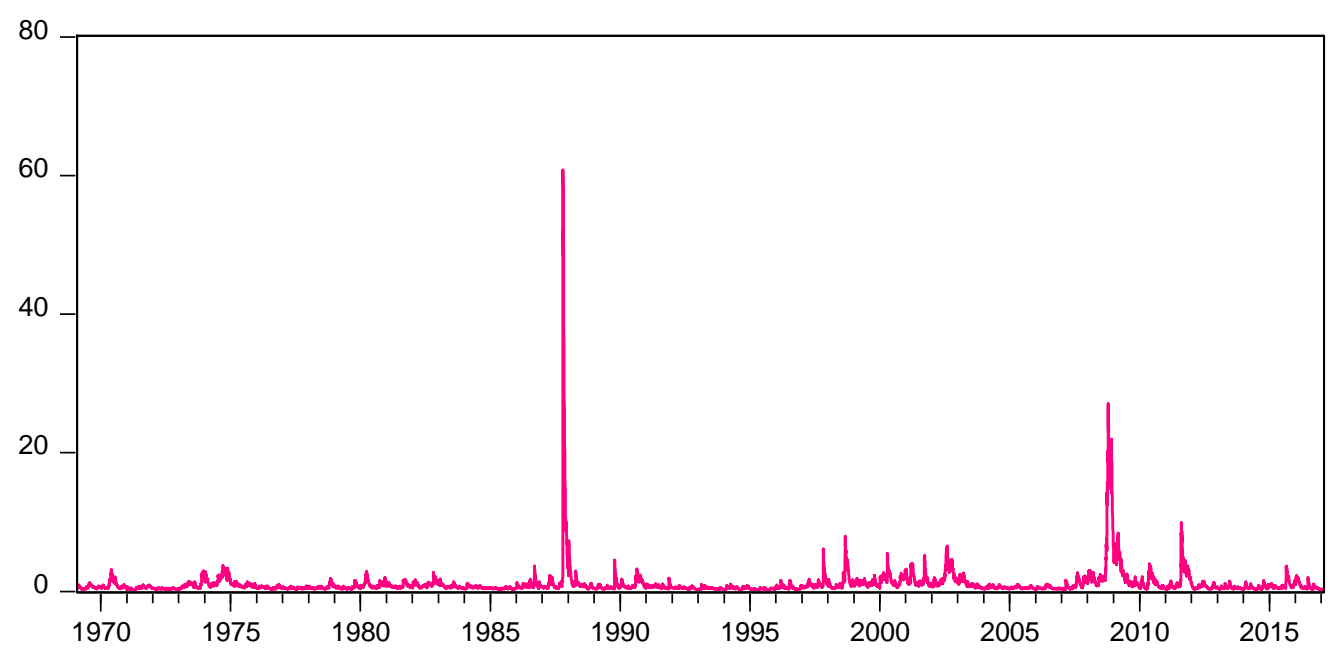

Panel B. Time-varying variances of Canadian equity index returns

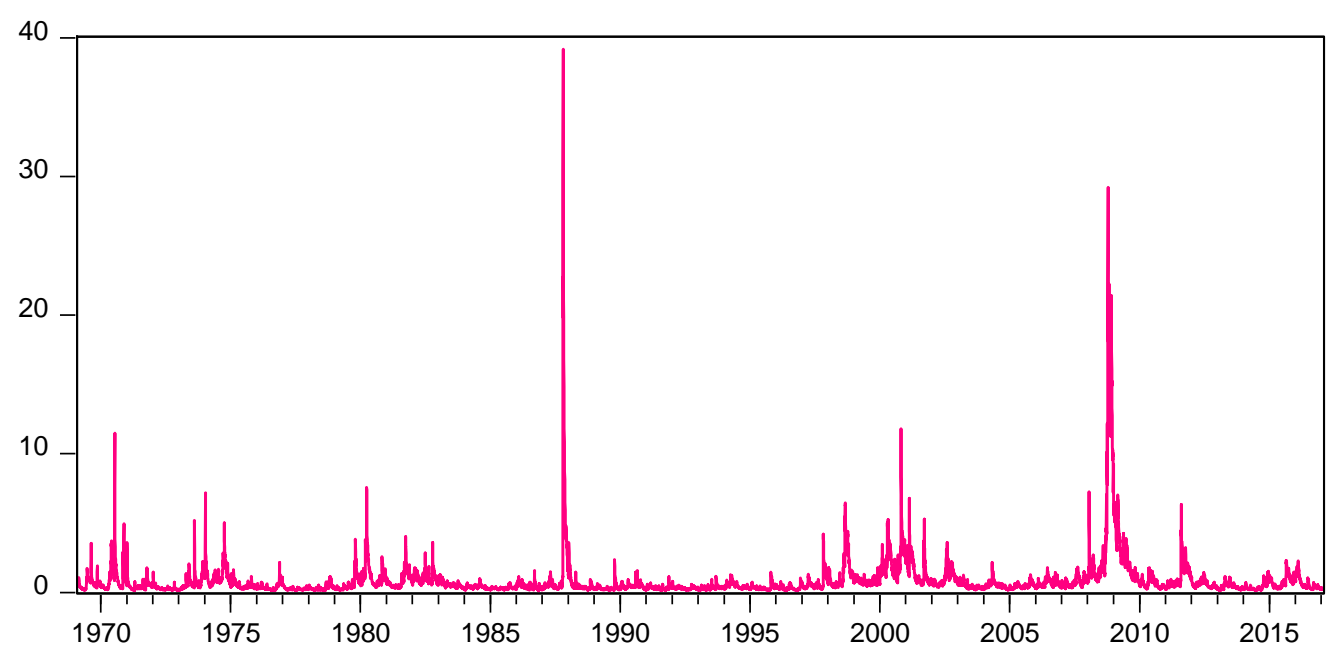

Panel C. Time-varying covariances of US and Canadian equity index returns

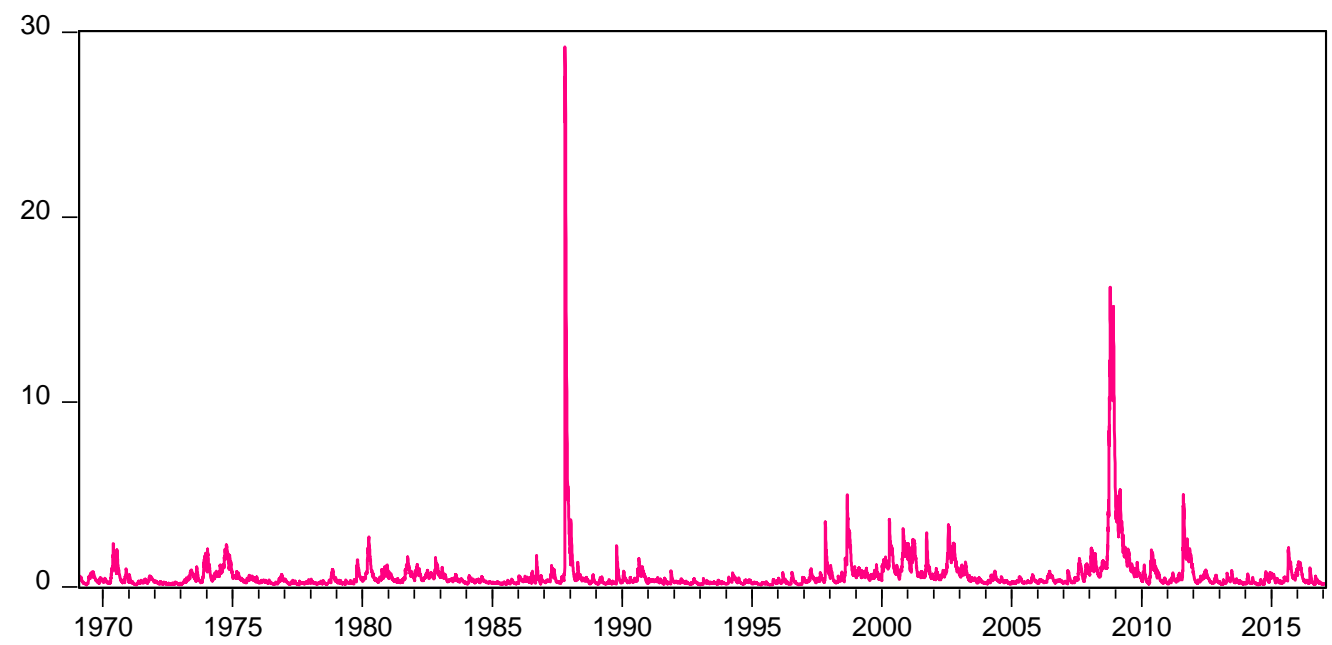

Figure 2. Dynamic evolution of the time-varying variances and covariances of US and Canadian equity index returns: For the period from February 4, 1969 to January 31, 2017 


\section{Interpreting the Case Results}

This section attempts to interpret our case results from US and Canadian equity market data. First, Table 1 presents the estimation results of our full VECH model with asymmetric effects. In Table 1, the coefficient of matrix C's $i$-th row and $j$-th column is written as $\mathrm{C}(i, j)$; the coefficient of matrix $\mathbf{A}$ 's $i$-th row and $j$-th column is written as $\mathrm{A}(i, j)$; the coefficient of matrix B's $i$-th row and $j$-th column is written as $\mathrm{B}(i, j)$; and the coefficient of matrix $\mathbf{D}$ 's $i$-th row and $j$-th column is written as $\mathrm{D}(i, j)$, respectively. These coefficients and four matrices are those in our full VECH model (1). The results in Table 1 indicate that our full VECH model with asymmetric effects is generally well estimated.

Moreover, Figure 2 exhibits the dynamic evolution of the time-varying variances and covariances of US and Canadian equity index returns analyzed in this paper. More concretely, Panel A of Figure 2 exhibits the time-varying variances of US equity index returns; Panel B of this figure displays the time-varying variances of Canadian equity index returns; and Panel $\mathrm{C}$ of this figure exhibits the time-varying covariances of US and Canadian equity index returns. These series are all shown for the period from February 4, 1969 to January 31, 2017. As to these series, we below attempt to interpret our full VECH model estimates.

\subsection{Variances of US Equity Index Returns}

We begin by interpreting the estimates for the variance of the return of first asset, the US equity index. We interpret and explain our results by focusing only on statistically significant estimates. Regarding the effects of shocks in mean equations, as seen in Table 1, the positive statistically significant $A(1,1)$ of 0.0141 means a shock to the US equity index return affects its own variance in the next day positively.

Second, as for the effects of variances and covariance, the positive statistically significant $B(1,1)$ of 0.9497 indicates an increase of the US equity index return variance increases its own variance in the next day and the positive statistically significant $B(1,3)$ of 0.0307 means an increase of the Canadian equity index return variance ups the US equity index return variance in the next day. As shown in Panel $\mathrm{C}$ of Figure 2, as positive two asset covariances can be assumed, the statistically significant negative $B(1,2)$ of -0.0795 means an increase of the two asset covariance decreases the US equity index return variance in the next day. Further, as to the asymmetric effects, the statistically significant positive $D(1,1)$ of 0.1037 means a negative shock to the US equity index return increases its own variance in the next day.

\subsection{Variances of Canadian Equity Index Returns}

Next, we interpret the estimates for the variance of the return of second asset, the Canadian equity index. First, the statistically significant positive $A(3,1)$ of 0.0638 means a shock to the US equity index return affects the Canadian equity index return variance in the next day positively. Further, the statistically significant positive $A(3,3)$ of 0.1509 suggests a shock to the Canadian equity index return affects its own variance in the next day positively.

With regard to the effects of variances and covariance, the statistically significant negative $B(3,1)$ of -0.4005 indicates an increase of the US equity index return variance decreases the Canadian equity index return variance in the next day; and the statistically significant positive $B(3,3)$ of 0.5065 means an increase of the Canadian equity index return variance ups its own variance in the next day. Assuming positive two asset covariances as in Figure 2, the statistically significant positive $B(3,2)$ of 1.0524 means an increase of the two asset covariance increases the Canadian equity index return variance in the next day. Further, as for the asymmetric effects, the statistically significant positive $D(3,1)$ of 0.0466 means a negative shock to the US equity index return increases the Canadian equity index return variance in the next day; and the statistically significant positive $D(3,3)$ of 0.0278 means a negative shock to the Canadian equity index return ups its own variance in the next day.

\subsection{Covariances of US and Canadian Equity Index Returns}

Next, we interpret the estimates for the covariance of the two assets. Again, we interpret and explain our results by focusing only on statistically significant estimates. As for the effects of variances and covariance, the statistically significant positive $B(2,1)$ of 0.0246 indicates an increase of the US equity index return variance ups the covariance in the next day and the statistically significant positive $B(2,3)$ of 0.0444 means an increase of the Canadian equity index return variance increases the covariance in the next day.

Assuming positive two asset covariances, the statistically significant positive $B(2,2)$ of 0.8396 means an increase of the two asset covariance ups the covariance in the next day. Further, as to the asymmetric effects, the statistically significant positive $D(2,1)$ of 0.0464 means a negative shock to the US equity index return increases the covariance in the next day and the statistically significant positive $D(2,3)$ of 0.0146 means a negative shock to the Canadian equity index return ups the covariance in the next day. 


\section{Conclusions}

After the development by Bollerslev et al. (1988), VECH models have not been used so often in empirical research. This paper attempted to conduct careful general interpretations of the parameter estimates of the full VECH model with asymmetry. We also considered the case of US and Canadian equity index returns by applying the model. More concretely, we firstly inspected the model formula and derived the general interpretation of the model parameters. We consider this is particularly useful for understanding the full VECH model and other MGARCH models, for example, BEKK (Engle and Kroner, 1995) and DCC models (Engle, 2002). Very recent applications for the VECH model, the BEKK model, and the DCC model are seen for example in Tsuji (2017a), Tsuji (2017b), and Tsuji (2016), respectively. After the above general considerations of the full VECH model, we also interpreted the case results that were derived from our application of this model to US and Canadian equity index returns. We consider that these illustrations are also very helpful.

As we mentioned above, our general and case result interpretations exhibited in this paper shall be helpful for deepening our understanding of MGARCH models and their applications to the real-world international financial markets. Hence, our demonstrations and illustrations conducted in this paper shall be useful for future empirical studies as to financial markets by using similar econometric models. Thus, extending this kind of research with highly clear interpretation of its empirical result by using other data sets is one of our important future works.

\section{Acknowledgements}

The author greatly appreciates this journal for the repeated kind article invitation. In addition, the author greatly thanks Susan Sun for her kind editorial assistance to this paper. I also thank the Chuo University Grant for Special Research for the generous financial support to this research. Furthermore, I highly appreciate anonymous referees for their supportive comments on this paper and finally, I deeply thank all the Editors of this journal for their kind attention to this paper.

\section{References}

Baillie, R. T., \& Myers, R. J. (1991). Bivariate garch estimation of the optimal commodity futures hedge. Journal of Applied Econometrics, 6, 109-124. http://onlinelibrary.wiley.com/doi/10.1002/jae.3950060202/pdf

Bollerslev, T., Engle, R. F., \& Wooldridge, J. M. (1988). A capital asset pricing model with time-varying covariances. Journal of Political Economy, 96, 116-131. https://doi.org/10.1086/261527

Degiannakis, S., Filis, G., \& Floros, C. (2013). Oil and stock returns: Evidence from European industrial sector indices in a time-varying environment. Journal of International Financial Markets, Institutions \& Money, 26, 175-191. https://doi.org/10.1016/j.intfin.2013.05.007

Engle, R. F. (2002). Dynamic conditional correlation: A simple class of multivariate generalized autoregressive conditional heteroskedasticity models. Journal of Business \& Economic Statistics, 20, 339-350. http://dx.doi.org/10.1198/073500102288618487

Engle, R. F., \& Kroner, K. F. (1995). Multivariate simultaneous generalized Arch. Econometric Theory, 11, 122-150. https://doi.org/10.1017/S0266466600009063

Ferreira, M. A. (2005). Forecasting the comovements of spot interest rates. Journal of International Money and Finance, 24, 766-792. https://doi.org/10.1016/j.jimonfin.2005.04.004

Füss, R., Mager, F., Wohlenberg, H., \& Zhao, L. (2011). The impact of macroeconomic announcements on implied volatility. Applied Financial Economics, 21, 1571-1580. http://dx.doi.org/10.1080/09603107.2011.583216

Guo, Z. Y. (2017). How information is transmitted across the nations? An empirical investigation of the US and Chinese commodity markets. Global Journal of Management and Business Research, 17, 1-11. http://dx.doi.org/10.17406/GJMBR

Jayasinghe, P., Tsui, A. K., \& Zhang, Z. (2014). New estimates of time-varying currency betas: A trivariate BEKK approach. Economic Modelling, 42, 128-139. http://dx.doi.org/10.1016/j.econmod.2014.06.003

Sadorsky, P. (2012). Correlations and volatility spillovers between oil prices and the stock prices of clean energy and technology companies. Energy Economics, 34, 248-255. https://doi.org/10.1016/j.eneco.2011.03.006

Tsuji, C. (2016). Does the fear gauge predict downside risk more accurately than econometric models? Evidence from the US stock market. Cogent Economics \& Finance, 4, 1-42. http://dx.doi.org/10.1080/23322039.2016.1220711 
Tsuji, C. (2017a). A quantitative investigation of the time-varying beta of the international CAPM: The case of North American and European equity portfolios. Journal of Management Research, 9, 104-112. https://doi.org/10.5296/jmr.v9i2.10937

Tsuji, C. (2017b). An exploration of the time-varying beta of the international capital asset pricing model: The case of the Japanese and the other Asia-Pacific stock markets. Accounting and Finance Research, 6, 86-93. https://doi.org/10.5430/afr.v6n2p86 